\title{
Hypercholesterolaemia: not all cases warrant treatment
}

\author{
Jane Patmore, Sean Coyle, Richard Jones, Gilbert Wieringa
}

\section{Consider hyper- $\alpha-$ lipoproteinaemia before starting lipid lowering drugs in patients with high total serum cholesterol concentrations}

Department of Chemical Pathology, St James's University Hospital, Leeds LS9 7TF

Jane Patmore, registrar

Sean Coyle, senior registrar

Department of Chemical Pathology, Leeds General Infirmary, Leeds LS1 3EX Richard Jones, consultant

Department of Chemical Pathology, Christie Hospital, Manchester M20 9BX

Gilbert Wieringa, principal biochemist

Correspondence to: Dr Patmore.

$B M F$ 1993;307:1125-6
Increasing numbers of patients are being treated for hypercholesterolaemia on the basis of total cholesterol concentrations. We describe a 49 year old woman so treated whose high total cholesterol concentration was explained by a high density lipoprotein cholesterol concentration of $3.9 \mathrm{mmol} / \mathrm{l}$ and a serum apoprotein AI concentration of $2.75 \mathrm{~g} / \mathrm{l}$; this indicated hyper- $\alpha$ lipoproteinaemia, a condition with no association with cardiovascular disease.

\section{Case report}

Following routine health screening by her general practitioner a 49 year old woman was found to have a raised serum total cholesterol concentration of $9.4 \mathrm{mmol} / \mathrm{l}$. She had not smoked for 15 years, was not diabetic, was of normal weight, took regular exercise, and had no family history of ischaemic heart disease. She had no symptoms suggestive of cardiovascular disease and on examination had no corneal arcus and tendinous or cutaneous xanthomas. Her electrocardiogram was normal.

Her medical history included successful renal transplantation at the age of 37 and a total hysterectomy at the age of 45 followed by the start of hormone replacement treatment. One year later she was found to be moderately hypertensive and was started on a cardioselective $\beta$ blocker (metoprolol). Her other medications were prednisolone (enteric coated) $10 \mathrm{mg}$ twice daily, azathioprine $125 \mathrm{mg} /$ day, and piperazine oestrone $1.5 \mathrm{mg} /$ day.

After the finding of hypercholesterolaemia she was placed on a cholesterol lowering diet and her total cholesterol concentration fell to $8.1 \mathrm{mmol} / 1$ over the next two months. No further reduction was achieved, however, and treatment with bezafibrate was started. Eight weeks later her cholesterol concentration remained at $8.2 \mathrm{mmol} / \mathrm{l}$, and simvastatin $10 \mathrm{mg}$ at nigh was substituted. This reduced her total cholesterol concentration to $7 \cdot 1 \mathrm{mmol} / \mathrm{l}$, where it fell within the range for triggering low density lipoprotein cholesterol estimation.

Since April 1991 our laboratory computer at St James's University Hospital has been programmed automatically to request high density lipoprotein cholesterol and triglyceride analyses when the total cholesterol concentration is between 6.5 and $7.8 \mathrm{mmol} / 1$. These are then used to calculate low density lipoprotein cholesterol values (by the Friedewald equation ${ }^{1}$ ).

The values obtained were: high density lipoprotein cholesterol $3.9 \mathrm{mmol} / \mathrm{l}$, low density lipoprotein cholesterol $2.8 \mathrm{mmol} / \mathrm{l}$, triglyceride $0.8 \mathrm{mmol} / \mathrm{l}$, and serum apoprotein AI concentration $2 \cdot 75 \mathrm{~g} / \mathrm{l}$. High density lipoprotein cholesterol was measured by the magnesium-phosphotungstate precipitation method and apoprotein AI by rocket immunoelectrophoresis. This concentration of low density lipoprotein cholesterol carries a low risk for cardiovascular disease so the simvastatin was stopped. A subsequent sample, taken several months later, showed: total cholesterol $9 \cdot 1$ $\mathrm{mmol} / \mathrm{l}$, low density lipoprotein cholesterol $4.9 \mathrm{mmol} / \mathrm{l}$, high density lipoprotein cholesterol $3.6 \mathrm{mmol} / \mathrm{l}$, triglyceride $1.37 \mathrm{mmol} / \mathrm{l}$, and apoprotein AI $2.85 \mathrm{~g} / 1$.
The serum high density lipoprotein cholesterol and apoprotein AI concentrations in the patient's two offspring were normal.

The rise in low density lipoprotein cholesterol from $2.8 \mathrm{mmol} / 1$ to $4.9 \mathrm{mmol} / 1$ was consistent with the withdrawal of simvastatin therapy. Although the patient's low density lipoprotein cholesterol concentration is now greater than $4.0 \mathrm{mmol} / \mathrm{l}$, the desirable limit of the European Atherosclerosis Society guidelines, ${ }^{2}$ her full lipid profile and medical history indicates a low risk of cardiovacular disease that does not warrant the use of lipid lowering drugs. Nevertheless, the patient should continue to follow advice appropriate to the whole population on diet, weight, and exercise, and further lipid assessment will be required with any change in her drug therapy.

\section{Discussion}

This patient illustrates the danger of viewing every patient with hypercholesterolaemia as a high risk candidate for cardiovascular disease. Treatment with such potent long term therapies as the hydroxymethyl glutaryl coenzyme A reductase inhibitors carries risks, including rhabdomyolysis, hepatitis, insomnia, and abdominal pain. ${ }^{3}$ The guidelines of the European Atherosclerosis Society and the British Hyperlipidaemia Association draw attention to the value of measuring high density lipoprotein cholesterol and low density lipoprotein cholesterol to assess an individual patient's need for medical care. ${ }^{4}$ On screening a general practice population Neil et al found that $16 \%(23 \%$ women $v 9 \%$ men) of those with a total cholesterol concentration of $6.5 \mathrm{mmol} / \mathrm{l}$ or more and a normal triglyceride concentration had a high density lipoprotein cholesterol of $2.0 \mathrm{mmol} / /$ or more and thus a lower cardiovacular risk than suggested by their total cholesterol concentration alone. 5

The concentration of high density lipoprotein cholesterol may in fact be very high. Koizumi et al described a patient with a concentration of $7.83 \mathrm{mmol} / 1 .^{6}$ In this and other series the hyper- $\alpha$ lipoproteinaemia was accompanied by a moderate increase in the total cholesterol concentration with normal low density lipoprotein cholesterol and triglyceride concentrations. ${ }^{67}$ This increase in high density lipoprotein cholesterol may be secondary to other conditions such as alcoholism, inhalation of chlorinated hydrocarbon pesticides, and oestrogen administration, ${ }^{8-10}$ or it may be primary. Primary hyper- $\alpha$-lipoproteinaemia is generally held to be inherited as an autosomal dominant trait associated with longevity. ${ }^{71}$ In our patient hormone replacement therapy with an unopposed oestrogen might have caused the hyper- $\alpha$-lipoproteinaemia. ${ }^{710}$

Identifying patients with hyper- $\alpha$-lipoproteinaemia is clearly desirable as they may then be spared anxiety and expensive drug therapy. Measurement of high density lipoprotein cholesterol by laboratories in the United Kingdom, however, is often carried out on a random basis with wide differences in requesting patterns. ${ }^{12}$ High density lipoprotein cholesterol concentrations are more complex and expensive to measure than total cholesterol or triglyceride 
concentrations, and in practice their measurement may be limited to those patients in whom a particularly high or low result is likely to alter their risk status-that is, those with moderate hypercholesterolaemia. Accordingly we have standardised our criteria for assaying high density lipoprotein cholesterol, and a fortunate result has been the identification of this patient with hyper- $\alpha$-lipoproteinaemia, a case of hypercholesterolaemia not warranting treatment.

1 Warnick GR, Knopp RH, Fitzpatrick V, Branson L. Estimating low-density lipoprotein cholesterol by the Friedewald equation is adequate for classifying patients on the basis of nationally recommended cutpoints. Clin Chem 1990;36:15-9.

2 European Atherosclerosis Society. The recognition and management of hyperlipidaemia in adults: a policy statement of the European Atherosclerosis Society. Eur Heart f 1988;9:571-600.

3 British National Formulary 25. London: British Medical Association and Royal Pharmaceutical Society of Great Britain, 1993:113.

4 Shepherd J, Betteridge DJ, Durrington P, Laker M, Lewis B, Mann J, et al. Strategies for reducing coronary heart disease and desirable limits for blood lipid concentrations: guidelines of the British Hyperlipidaemia Association BMF 1987;295:1245-6.

5 Neil HAW, Mant D, Jones L, Morgan B, Mann JI. Lipid screening: is it enough to measure total cholesterol concentration? $B M F$ 1990;301:584-7.

6 Koizumi J, Mabuchi $\mathrm{H}$, Yoshimura A, Michishita I, Takeda M, Itoh $\mathrm{H}$, et al. Deficiency of serum Deficiency of serum cholesteryl-ester transfer activity in patie
familial hyperalphalipoproteinaemia. Atherosclerosis 1985;58:175-86.

7 Glueck CJ, Fallat RW, Millett F, Gartside P, Elston RC, Go RCP. Familia hyper-alpha-lipoproteinaemia studies in eighteen kindreds. Metabolism 1975;24:1243-65.

8 Johansson BG, Laurell CB. Disorders of serum alpha-lipoproteins after alcoholic intoxication. Scand $\mathcal{9}$ Clin Lab Invest 1969;23:231-3.

9 Carlson LA, Kolmodin-Hedman B. Hyper-alpha-lipoproteinemia in men exposed to cholorinated hydrocarbon pesticides. Acta Med Scand 1972;192: 29-32.

10 Gustafson A, Svanborg A. Gonadal steroid effects on plasma lipoproteins and individual phospholipids. $f$ Clin Endocrin and Met 1972;35:203-7.

11 Glueck CJ, Gartside P, Fallat RW, Sielski J, Steiner PM. Longevity syndromes-familial hypobeta and familial hyperalphalipoproteinemia. ${ }^{f}$ Lab Clin Med 1976;88:941-57.

12 Laker MF. Reckless JPD, Betteridge DJ, Durrington PN, Miller JP, Nicholls $\mathrm{DP}$, et al. Laboratory facilities for investigating lipid disorders in the United Kingdom: results of the British Hyperlipidaemia Association Survey. I Clin Path 1992;45:102-5.

(Accepted 14 fune 1993)

\section{Grand Rounds-Hammersmith Hospital}

\section{Diabetes and rhabdomyolysis}

\section{A rare complication of a common disease}

Rhabdomyolysis is common in diabetic patients with hyperosmolarity, although it is not always tested for. The most sensitive marker of muscle cell damage is serum creatine kinase concentration, which seems to correlate with the degree of damage incurred. ${ }^{1}$ Acute renal failure secondary to rhabdomyolysis is well recognised, but an association with hypersmolarity has been reported in only a few cases. We present the case of a man who developed acute renal failure secondary to rhabdomyolysis with diabetic hyperosmolarity and discuss possible mechanisms that might have caused it.

\section{Case history}

A 47 year old Afro-Caribbean man presented to his Department of Medicine, Royal Postgraduate Medical School, Hammersmith Hospital, London W12 0NN Case presented by: G M Lord, senior house officer in nephrology

\section{Chairman:}

James Scott, professor of medicine

Discussion group: C D Pusey, reader in renal medicine

A J Rees, professor of nephrology

M J Walport, professor of rheumatology

K A A Davies, senior lecturer in rheumatology

C Bulpitt, professor of geriatrics

S R Bloom, professor of endocrinology

F M Muntoni, lecturer in paediatrics

Series edited by: Dr Moira Whyte. oxygen tension $19 \mathrm{kPa}$, arterial carbon dioxide tension $2.7 \mathrm{kPa}$, and base excess -15 . Urine analysis detected glucose and blood cells but no ketones. Urine microscopy showed five white cells and 40 red cells per high power field with occasional granular casts. Electrocardiography showed a sinus tachycardia with a rate of 150 beats per minute and his chest radiograph appeared normal. Renal ultrasonography showed normal sized kidneys with no evidence of obstruction.

$\mathrm{He}$ was rehydrated with intravenous fluids and his diabetes was controlled by giving insulin according to a sliding scale. He became oliguric despite good filling pressures and was therefore started on renal dose dopamine $(3 \mu \mathrm{g} / \mathrm{kg} / \mathrm{min})$ and frusemide with dextroseinsulin and Calcium Resonium to control his hyperkalaemia. Four days after his admission he was transferred to our hospital because of persistent acidosis, hyperkalaemia, oliguria, and worsening renal failure.

On arrival he had impaired consciousness, had no fever, and was haemodynamically stable. There was no muscle tenderness or swelling. His renal failure had progresed such that his creatinine concentration was $1000 \mu \mathrm{mol} / 1$ with concomitant acidosis and hyperkalaemia. His serum creatine kinase concentration was $100000 \mathrm{IU} / \mathrm{l}$ and he had raised aspartate aminotransferase and uric acid concentrations. His serum phosphate concentration was towards the upper end of the normal range at $1.35 \mathrm{mmol} / \mathrm{l}$ and he had myoglobinuria. Other investigations done to test for acute renal failure gave normal results. A toxicological screen and viral serology gave negative results. A muscle biopsy during the acute phase of his illness showed that the overall structure of the muscle was well preserved. There were a few small fibres with basophilic staining and large central nuclei that were regenerative in origin, indicating recent muscle injury (fig 1; top). The fibre type and glycogen content were normal and no lipid accumulation was found (fig 1 ; bottom).

We therefore diagnosed acute renal failure secondary to rhabdomyolysis with an associated non-ketotic diabetic state. He was given intravenous insulin and prophylactic heparin and remained dependent on dialysis for three weeks. He was discharged from hospital seven weeks after admission requiring no drugs. His diabetes was controlled by diet alone. Figure 2 shows the changes in serum creatinine and urine output with time. He became polyuric at around day 30 , but his urine volumes returned to normal 